\title{
UNA LECTURA HISTÓRICA DE «THE SCARLET HOUSE» DE ANGELA CARTER
}

\author{
EMILIO José Álvarez CASTAÑo \\ Zhejiang Yuexiu University of Foreign Languages
}

\section{Resumen}

La obra de Angela Carter ha sido estudiada habitualmente desde puntos de vista feministas y desde aspectos postmodernistas como la reescritura de cuentos de hadas. Sin negar este hecho, el presente artículo quiere destacar la importancia de la Historia en la obra de Carter centrándose en el análisis de su relato «The Scarlet House». Las ideas que tenía Carter sobre la Historia, enmarcadas muchas de ellas en la postmodernidad, pueden encontrar acomodo en diferentes teorías dentro de la filosofía de la Historia, lo que permitiría una interpretación en clave histórica de esta narración, un hecho que la propia Carter admite al aceptar la multiplicidad de lecturas en una obra literaria.

Palabras clave: Angela Carter, «The Scarlet House», Historia, Filosofía de la Historia, postmodernidad.

\section{A HISTORICAL READING OF ANGELA CARTER'S «THE SCARLET HOUSE»}

\begin{abstract}
Angela Carter's work has been usually studied from feminist points of view and from postmodernist aspects as the rewriting of fairy tales. Without denying this fact, this paper wants to underline the importance of History in Angela Carter's work focusing on the analysis of her short story «The Scarlet House». Carter's ideas on History, most of them framed in postmodernity, can find a suitable place among different theories within philosophy of History, something which will allow a historical reading of this short story. This type of interpretation was admitted by Carter herself when she accepted the multiplicity of readings for the same literary work.

Keywords: Angela Carter, «The Scarlet House», History, Philosophy of History, postmodernity.
\end{abstract}

Fecha de recepción: 11 de enero de 2020.

Fecha de aceptación: 4 de mayo de 2020. 


\section{INTRODUCCIÓN}

En la producción literaria de Angela Carter (1940-1992) descuellan dos aspectos que han sido señalados en diversos estudios sobre su obra, como son el feminismo y la reescritura que hizo de algunos cuentos de hadas y folklóricos, aunque también se han destacado y analizado otros aspectos y elementos, como el circo, las marionetas, el vampirismo (Botelho, 2016), la casa, la parodia, lo gótico (Pérez Gil, 1996: 96 sigs.), y la hipertextualidad (Crunelle-Vanrigh, 2001: 142). Sin negar la relevancia de este hecho, el presente estudio pretende resaltar la importancia del fenómeno histórico en diferentes obras de esta autora como preámbulo a una propuesta de lectura en clave histórica de su relato «The Scarlet House» (1977). Esta narración admite una interpretación de tipo feminista de la misma forma que también se han realizado otras propuestas interpretativas que incluyen la teoría del caos (García Barrera, 1999), o sobre la intención de la protagonista por mantener su espacio para preservar su propia naturaleza (Kérchy, 2019). Desde estas líneas se defenderá la pertinencia de una lectura histórica que ayudará a resaltar la importancia de este aspecto en la obra de Angela Carter y, a la vez, proporcionará un enfoque alternativo de «The Scarlet House», todo ello dentro del contexto postmoderno en el que se sitúa la autora.

\section{LA HISTORIA EN ANGELA CARTER}

El interés que tenía Angela Carter por la Historia está ya presente en su obra ensayística. En 1971 publicó The Sadeian Woman, subtitulado An Exercise in Cultural History, que comienza de la siguiente forma:

Pornographers are the enemies of women only because our contemporary ideology of pornography does not encompass the possibility of change, as if we were the slaves of history and not its masters, as if sexual relations were not the result of social relations, as if sex itself were an external fact, one as immutable as the weather, creating human practice but never part of it (Carter, 2001: 3-4).

Este planteamiento feminista apunta a aquellos hechos y personas que han quedado fuera de la historia oficial. Esta idea tiene su prolongación en los textos de ficción. Dentro de su faceta como editora de cuentos de hadas, en 
la introducción a una obra que recogía dos volúmenes que publicó con anterioridad, Carter (2005: xii) señalaba que la historia, la sociología y la psicología que estas narraciones transmitían a los lectores era siempre la no oficial, por lo que pone en valor estos aspectos que no son recogidos por la historiografía.

Ya como novelista, Nights at the Circus (1984) se encuadra en lo que Linda Hutcheon (2004: 113-114) llamó la «historiographic metafiction», cuyos protagonistas «are the ex-centrics, the marginalized, the peripheral figures of fictional history», una idea sobre la que vuelve a reflexionar en Wise Children (1991), una obra que se ha llegado a definir de la siguiente forma:

[A]s a text that deals with the histories of those who have been oppressed in society rather than a single true «History» with a capital H. Instead of depicting men's or rulers' history, Dora focuses on the lives of the poor and working-class women as well as on the so-called «low» cultures, from music halls to TV shows (Okuhata, 2019: 264).

Shakespeare es utilizado aquí como el paradigma de lo que se estima como Arte o Cultura, en comparación con otras manifestaciones artísticas que no gozan de la misma consideración, aunque se recuerda que no siempre fue así. Shakespeare es el vínculo entre las familias Hazard y Chance, entre la cultura oficial y la popular ya que, aunque ahora sea uno de los iconos de la identidad cultural inglesa, sus obras fueron representadas entonces en el South Bank londinense (Calvo, 2012: 165).

Se trata de una defensa de lo que dentro de la narrativa Barthes (1984: 184) llamó «residuos», pero que, gracias al detalle y al grado de minuciosidad que pueden alcanzar, se presentan como parte indispensable para lograr el llamado "efecto de realidad», de ahí que el filósofo francés llegara a la conclusión de que el discurso histórico y la prosa de ficción presenten el mismo grado de credibilidad (Vlitos, 2017: 1400-1401). En la producción de Angela Carter, el relato «The Fall River Axe Murders» explora la línea que divide la prosa de ficción del discurso histórico y utiliza de manera repetida el recurso de los olores para caracterizar fidedignamente una época pasada. La irresolución de lo acontecido en el conocido caso de los asesinatos en casa de Lizzie Borden y las diferentes versiones que se dieron al respecto supusieron un material ideal para que Carter reflexionara sobre dónde radica la realidad de los hechos históricos. 
Dos años antes, en 1983, llegó a afirmar en otro escrito suyo: «I try, when I write fiction, to [...] present a number of propositions in a variety of different ways, and to leave the reader to construct her own fiction from the elements of my fictions» (Carter, 2013: 45). Resulta lógico que la figura del vampiro sea uno de los elementos recurrentes en su obra, ya que se trata de seres en los que se combina la historia con la ficción pues, al no estar ni vivos ni muertos, están en la frontera de ambos, son simultáneamente bestias y humanos (Botelho, 2016: 293-294). En el caso del citado relato, al ofrecer distintas narraciones sobre los mismos hechos, que funcionarían como hipertextos, Carter procuraba poner al lector en el lugar de un investigador ante un archivo histórico para que acabara cuestionándose la validez del término real cuando se estudia el pasado histórico (Ricoeur, 1988: 142), por no decir que documenta la desaparición del conocimiento histórico (Berni, 1997: 49). Carter se burla del intento por alcanzar la objetividad histórica cuando enumera de forma exagerada e irónica las posibles causas del asesinato. Al admitir la imposibilidad de alcanzar la verdad histórica, Carter defiende que la Historia es inaccesible a menos que se haga de una manera textual (Jameson, 2002: 67). Por este motivo, en esta versión sobre lo sucedido a la familia Borden, Carter sugiere que Lizzie construya su realidad basándola en las realidades emocionales de los cuentos de hadas (Berni, 1997: 52), y que la forma en la que se produce la Historia es por medio de un catálogo de conocimientos recibidos donde se mezclan narraciones históricas y ficticias (Berni, 1997: 53). Posteriormente se comentarán más detalles sobre este aspecto.

Por tanto, a la escritura de unos hechos le pueden suceder diferentes reescrituras y versiones. En la obra de Angela Carter se encuentran narraciones que mezclan rasgos de los cuentos de hadas y folklóricos, la pornografía, la mitología, la picaresca, entre otras obras. Un ejemplo al respecto se tiene en «The Bloody Chamber» (1979), del que se ha documentado su riqueza alusiva (Mătel-Boatcă, 2011: 60-71; Roemer, 1998), para, a partir de ahí, alabar cómo esta cualidad del texto como palimpsesto tiene una importante función pedagógica al ayudar al lector a descifrar aquellos significados que se encuentran ocultos (Dutheil, 2013: 111), algo que sucede gracias a este carácter hipertextual que lleva a reinterpretaciones y recreaciones (Bacchilega, 2015: 79), como también sucede en «The Courtship of Mr Lyon» 0 «The Tiger's Bride». Por ello se ha afirmado que la escritura de Angela Carter es un palimpsesto de significados donde cada interpretación puede dar paso a la siguiente (Filimon, 2014: 176). Desiderio, el protagonista de The Infernal Desire Machines 
of Doctor Hoffman (1972), tiene que elegir entre la realidad y sus deseos y acaba considerado como un héroe de guerra por la Historia pero, en toda la narración en primera persona, Carter apunta de manera repetida a una serie de hechos que no tienen un seguimiento completo en el texto, con lo que el lector puede vincular esta situación con la que él está viviendo al verse influenciado por las distintas versiones de la realidad que le llegan y que afectan a sus ideas, creencias y emociones.

Todas estas ideas y afirmaciones carecerían de sentido sin la función que tiene la memoria en la construcción del discurso histórico. En Heroes and Villains (1969) hay un discurso feminista que surge frente a conceptos patriarcales, pero también se destaca la importancia de la memoria de cara al futuro en un mundo postapocalíptico. Por eso se ha afirmado:

It is certain that «history», to some extent, can remain in the written texts or records protected in the archives in the Professors' village, and the three groups might survive as «living corpses», even after the extinction of civilization. However, there will be no evolution or development for the people who have forgotten the nuclear war, or their «Original Sin» in the past (Okuhata, 2019: 143).

En plena Guerra Fría, Carter lanza esta advertencia que señala el fin de la Historia entendiéndolo como el fin de una idea de civilización en un momento en el que los seres humanos seguían sin ser conscientes de las consecuencias de una conflagración nuclear. Solo la mirada al pasado por medio de la memoria ayudaría a un nuevo comienzo.

La memoria se presenta como un elemento de importancia capital en «The Scarlet House». Es el elemento que el Conde quiere eliminar porque es la principal diferencia entre el ser humano y las bestias $(418)^{1}$. Frente al mundo de la casa en la que se encuentra recluida, la protagonista mantiene memorias familiares, como la foto de su madre, el recuerdo del parecido de los ojos de ambas y el padre reconstruyendo la tetera rota a partir de los diferentes pedazos, como se trata de reconstruir el pasado a partir de los trozos de memoria que se conservan. Cuando se percata de la imposibilidad de apelar a la memoria, la protagonista recurre al inconsciente, que es simbolizado

\footnotetext{
${ }^{1}$ Indicaremos en el trabajo únicamente las páginas de «The Scarlet House» (Carter, 2006: 417-428).
} 
en el halcón como la pista que tiene de su captura, preservado como una imagen, un icono. Siguiendo a Foucault, Carter apunta a que no es lo social y su imaginario colectivo lo que es terrible y peligroso sino el poder de este y la elección ético-política que se debe tomar cada día la que determina dicho peligro (Sempruch, 2008: 78). Y como la memoria es selectiva y puede estar deformada, la narradora busca orientación en aquellos conocimientos que ya tiene adquiridos en ciertos campos.

\section{MODELOS Y CAMPOS EPISTEMOLÓGICOS}

El Conde de «The Scarlet House» combate los intentos de la protagonista por recordar, por eso la azota cuando repite que tiene los mismos ojos de su madre y ríe cuando la ve confundida; sin embargo, le da una pista cuando confiesa lo siguiente: «Man is an animal who insists on making patterns, says the Count contemptuously; all the world you think so highly of is nothing but pretty floral wallpaper pasted up over chaos» (427). Justo a continuación es cuando emerge la imagen del halcón como ese modelo que busca ser una referencia en el caos. En un relato de un contenido tan altamente alusivo resulta complejo mencionar todas las posibles referencias, especialmente si se tiene en cuenta la multiplicidad de lecturas que admiten muchas obras de Angela Carter, algo que ella misma incentiva y admite. En una entrevista publicada en enero de 1985, llegó a afirmar: «Reading a book is like re-writing it for yourself. And I think that all fiction should be open-ended. You bring to a novel, anything you read, all your experience of the world. You bring your history and you read it in your own terms» (Carter, 1985: 20). Carter vivió en una sociedad postmoderna donde no hay valores absolutos ni leyes universales, sino que se depende de percepciones, de la interpretación individual. La cultura postmoderna está constituida de trozos que se tratan de organizar siguiendo modelos de los que extraer un significado, aunque este deseo de ordenar el material conocido lleve a otro tipo de ficción. Ya que el ser humano trata de sacar sentido del caos puesto que es la forma de crear una identidad (Botelho, 2016: 306), en este apartado se comentarán aquellos campos y modelos epistemológicos que forman parte de un entramado de conocimientos previos que pueden orientar a la narradora.

Llama la atención la presencia del mundo animal en «The Scarlet House», en muchas ocasiones atendiendo a cualidades simbólicas. Los zorros que se 
encuentran en New Bond Street (418) son animales que tienen el poder de crear espejismos (Chevalier y Gheerbrant, 2007: 1090); de hecho, la narradora asegura que nunca los vio y que solo sintió sus aullidos desde la casa. Más tarde se comprueba cómo el Conde hace que sus prisioneras acaricien un cerdo, un animal asociado a la glotonería (Mariño Ferro, 1996: 89), pero también a diversas tendencias oscuras (Chevalier y Gheerbrant, 2007: 275). En el relato se dice que vive en la basura (419), con lo que aparece como el animal ideal para reflejar ese proceso de entropía que quiere introducir el Conde, pero también porque al ser uno de los animales que devora a su propia prole es comparado con el mismo paso del tiempo.

La mariposa forma parte de la alegre decoración de la casa de la protagonista y está habitualmente relacionada con la transformación o la resurrección, un estado que debe alcanzar para salir de la situación en la que se encuentra, pero también puede apuntar a la muerte de una persona próxima (Chevalier y Gheerbrant, 2007: 691), como así sucede con el asesinato del padre. Antes de que esto suceda, se dice que el padre ha reconstruido una tetera que se había roto y que esta tiene el cuello de un cisne, animal vinculado a la epifanía o revelación (Chevalier y Gheerbrant, 2007: 306), que también necesita la protagonista para alcanzar la citada transformación.

Pero los animales no se emplean con esta única función. De Madame Schreck se dice que come «fig-peckers and thrushes» y fetos de conejos (419), y el Conde aparece en un póster cabalgando sobre una serpiente alada, con lo que en ambos casos caracterizan a dichos personajes en su grado de maldad. Y si la simbología puede apuntar a significados opuestos para un mismo elemento, como ocurre con el cisne y la mariposa, en «The Scarlet House» se muestran ambivalencias y cambios, de ahí que el Conde aparezca al principio del relato firmando con una pluma de un pavo real y al final de la narración dicha pluma sea de un halcón. Dicho animal, al caer sobre su presa, se puede asociar con la captura que sufrió la protagonista, para convertirse en ese icono ya referido y que la propia narradora indica que es un modelo (427).

Se puede seguir una intención similar en la utilización de los colores. Dentro de las distintas formas en las que Madame Schreck aparece ataviada, se la puede ver con un uniforme verde oliva para, poco después, aparecer vestida de rojo, color que la narradora identifica con la mujer (424), no en vano en su simbología está vinculado con la vida (Chevalier y Gheerbrant, 2007: 888). Es significativo que rápidamente el Conde la cubra con una bata azul (424), 
en una reacción relacionada con el espacio que ocupan. En cuanto a dicho espacio, al principio la narradora indica que la «Scarlet House» se parece a un hospital (418), por eso su color es blanco. Más tarde es identificada con un edificio que es granja y mansión al mismo tiempo y entonces su color es rojo (421), pero el color escarlata que le da nombre es una tonalidad del rojo que vendría a apuntar a las diferentes visiones o interpretaciones sobre una misma realidad. Se trata, además, de uno de los colores que aparece en la amable descripción de las flores de la casa paterna, donde están también el blanco y el rosa salmón de los geranios (421).

Las diferentes percepciones se deben a las pseudomemorias que el Conde instala en ella para provocar el caos, que ya gobierna en las ruinas gracias a las cartas del Tarot. El Tarot, debido a su carácter azaroso, no ofrece la misma credibilidad para todas las personas, de ahí que se le compare con el ajedrez. Igual que los príncipes medievales jugaban al ajedrez utilizando a sus vasallos como piezas, el Conde juega al Tarot de una forma peculiar en la que Madame Schreck sería la Papisa y el consejero sería el Loco, personaje que ya solo chilla y balbucea y casi ha olvidado como hablar, por lo que se encuentra cerca de esa indefinición que pretende el Conde para sus secuaces y prisioneros, y es que el Loco es el único arcano mayor que no tiene número en las cartas del Tarot. Por su parte, el propio Conde es descrito como un científico por la forma en la que enfoca el juego (424). Estos arcanos mayores fuerzan a participar a las prisioneras, que son los arcanos menores. Las vidas de estas mujeres se sitúan en una casa que es identificada ahora con un burdel en el que la memoria es la prostituta (424), y se enmarcan dentro de este sistema en el que aparecen y desaparecen por el deseo de sus captores (425). En el juego del Tarot, la combinación de la simbología de sus figuras, la numerología y los colores hace que las posibilidades de interpretación se multipliquen de nuevo.

Aunque la numerología forme parte del Tarot, también se puede encontrar en otros ámbitos como la cabalística. Así, los 22 años que tiene la protagonista es el mismo número de los arcanos mayores del Tarot, pero es además un número matemático, astrónomo y cabalístico (Albaigés, 2014: 95). Por otro lado, también tiene un recuerdo que parece claro de cuando tenía seis años, siendo este un número de completitud, al ser el primer perfecto y apuntar a la reunión y el equilibrio (Albaigés, 2014: 55). Pero, sobre todo, destaca la reiteración del número tres. Se trata de un número que tiene una gran presencia en las divinidades de algunas religiones, la mitología y en algunos cuen- 
tos de hadas. En «The Scarlet House», la triada formada por el Conde, Madame Schreck y el Loco aparece enfrentada a la narradora y los padres de esta. El currículum del Conde consta de tres puntos y para llevar a cabo su peculiar trivium ha instalado tres pseudomemorias en la mente de la protagonista con el objeto de que mezcle los tres tiempos, lo que supondría la implicación de que pasado y futuro son igual de ilusorios. Este ataque es combatido por la protagonista por medio de tres recuerdos mnemotécnicos.

Otro de los ataques del Conde tiene como objeto eliminar la lengua; para ello cuenta con la colaboración de Madame Schreck, cuyo nombre señala diversas implicaciones. Mientras que la palabra francesa Madame es un tratamiento de cortesía para dirigirse a una mujer, el apellido es de origen alemán y de género masculino (der Schreck), que significa miedo, con lo que se complementan nacionalidades y géneros para presentarla como la encarnación de la fertilidad, de ahí que las prisioneras tengan que rendir homenaje a su sexo y que sea un personaje que suele ir acompañado de referencias sexuales en sus apariciones. Por tanto, es también el personaje que se encuentra más cerca del caos, entendiéndolo aquí como origen del universo. En lo que se refiere al caos como ausencia de memoria y comunicación, Schreck puede evocar a to schriek, que significa chillar, no en vano una de sus funciones es la de gritar para el Conde (García Barrera, 1999: 139-140). Además, al final del relato, después de un pequeño ejercicio etimológico, la protagonista llega a la conclusión de que tuvo que aprender latín en algún momento de su vida (427). Llama la atención que, desde ese momento, aparezcan algunas palabras de raíz latina como ocurre con «elide», «concretisation», «declension», o que incluso se prefiera el uso de estos vocablos como «predicament»y «oubliette» (427-428), en vez de emplear las palabras inglesas awkwardy dungeon, respectivamente. Así, se presenta como otra arma para mantener viva su memoria.

Por último habría que referir aquellos conceptos e ideas de la Antigüedad Clásica. Se acaba de mencionar el caos como elemento generador y primigenio. Esta idea aparece en Hesíodo (Teogonía 116-122), en los primeros versos dedicados a la cosmogonía. En cuanto a la memoria, la narradora la presenta como la guía que ayuda a que no se pierda el camino, y lo ejemplifica con el personaje de Ariadna y la metáfora de tejer (418). En «The Scarlet House» el monstruo que se encuentra en el laberinto de la memoria es Madame Schreck, que es descrita de la siguiente forma: «[T] he Minotaur with the head of a woman and the orifice of a sow» (422), apareciendo de nuevo la referencia 
al cerdo como animal entrópico. Todo el proceso de eliminación de la memoria e imposición del ruido hace que las prisioneras lleven uno de sus dedos hacia la boca de una de las compañeras, como si quisieran asegurarse de que el hueco para el canal de comunicación continúe abierto, de ahí que la narradora se pregunta si no son ya sombras (425). Habría que cuestionarse lo mismo sobre las imágenes que la protagonista conserva del mundo exterior, como ocurre con los aullidos de los zorros o las dos versiones sobre la forma en la que fue capturada. En este sentido, es interesante la analogía con la alegoría de la caverna de Platón. En ella el autor se dirige a su interlocutor diciéndole: «En cuanto a la subida al mundo de arriba y a la contemplación de las cosas de éste, si las comparas con la ascensión del alma hasta la región inteligible no errarás con respecto a mi vislumbre, que es lo que tú deseas conocer» (Platón, 2004: 492), donde el propio Platón procura iluminar a Glaucón en sus conocimientos, algo que llega a considerar como un deber (Platón, 2004: 496-497). No es el único texto de Angela Carter vinculado con esta referencia. "The Lady of the House of Love», relato sobre el que se han señalado diversos hipertextos, ha sido estudiado tomando dicha alegoría para ahondar en consideraciones feministas (Pérez Gil, 2016). En cualquier caso, la alegoría de la caverna viene a hablar de la posición del ser humano frente al conocimiento y la relación existente entre el mundo sensible y el inteligible. Así, la protagonista de «The Scarlet House» desea su liberación para alcanzar una nueva realidad que le dé la clave de su actual estado cognitivo y también ayudar a sus compañeras de cautiverio.

Quedaría por comprobar si la clave que le permite a dicho personaje entender su posición está en la suma de todos estos conocimientos previamente adquiridos o si se puede añadir algún otro.

\section{LA FILOSOFÍA DE LA HISTORIA}

La filosofía de la Historia ha cuestionado el propósito u objetivo mismo de la Historia, la existencia de posibles patrones (como ciclos, progresos o regresiones), el motor de la Historia y la identidad del sujeto histórico. En este contexto, se comenzará por retomar las ideas apuntadas en el segundo apartado para luego analizar este aspecto de manera específica en «The Scarlet House». 
El primero de los aspectos ya comentados apuntaba a la atención que Angela Carter pide para aquellos grupos marginales a los que la Historia no les ha dado la suficiente importancia. Frente a la historia total, que solo atendía a los grandes nombres de la Historia, surgió la idea de plantear una historia individual en la que se le prestara atención a todas aquellas personas anónimas que también forman parte de la Historia y ayudan a construirla. Es un planteamiento que se encuentra en William Godwin (1756-1836) y en el Construccionismo, donde se procura romper con una concepción estratificadora de la Historia para darle mayor relevancia a aquellas personas que habitualmente han sido excluidas de ella (Donnelly y Norton, 2011: 40). El segundo punto comentaba la línea que separa la Historia de la ficción. El elemento ficticio se puede encontrar ya en algunas de las primeras manifestaciones historiográficas del mundo occidental. Heródoto no busca la verdad en su obra, sino que expone diversas noticias que le han llegado, por eso afirma en sus Historias (VII, 152): «Yo tengo la obligación de decir lo que se dice, en modo alguno tengo la obligación de creerlo en su totalidad; y esta afirmación téngase en cuenta para toda mi narración» (Heródoto, 1994: 692), incluso incluye las que él personalmente cree como falsas, ya que uno de sus objetivos es luchar contra el tiempo y el olvido (Gómez-Lobo, 1995: 4-6). El tercer aspecto se refería a la concepción de la Historia como palimpsesto. Ya Thomas Carlyle (1795-1881) comentaba esta idea de una acumulación de narrativas que se proyectaría hacia una metanarrativa histórica (McCaw, 2000: 83), lo que implicaría una profunda labor de interpretación y explicación de materiales entre los que se encuentra el folklore (Beneduce, 2017: 168). Por último, la memoria y las historias, aunque son elementos distintos, más que oponerse entre sí se enlazan, son partes constitutivas la una de la otra y lo pueden ser en múltiples direcciones (Lowenthal, 1998: 273). Pero la memoria también es sinónimo de imaginación, de forma que: «Thus, a personal memory transformed into an image can acquire historical status, and the images of popular culture have the capacity to affect personal memories» (Sturken, 1997: 65-66). Por tanto, se encuentra de nuevo la situación en la que el aspecto histórico y el personal se influencian mutuamente, como sucede con la referida imagen del halcón.

Algunas de estas ideas vuelven a aparecer en «The Scarlet House», como cuando la narradora indica que los borrados, sustituciones e imitaciones hacen que su memoria ahora sea un palimpsesto de posibilidades y probabilidades (424). Poco después recuenta el momento de su captura, que podría ser 
la de cualquiera de las otras prisioneras, por lo que dice experimentar que puede estar más cerca de «you all» (425), con lo que estaría apuntando a la intención de la historia individual. Por último, también es consciente de que el halcón y el hombre sin boca y los ojos sin rostro pueden no contener rasgos de una memoria real, son elementos inservibles, pero con significado si pudiese recordar, de ahí que concluya diciendo que son residuos (426), como los llamaba Barthes, pero, de nuevo, se trata de unos residuos que poseen la importancia que tienen los detalles por el significado que estos albergan.

Pero en «The Scarlet House» se pueden encontrar otras referencias de nuevo vinculadas a la filosofía de la Historia que vendrían a completar esta perspectiva.

Una de las imágenes por las que se ha tratado de explicar la Historia es la de las ruinas. Para Walter Benjamin (1892-1940), la ciudad, cuyo paradigma es París, hace posible vincular sus ruinas con la memoria, tratando de relacionar el pasado con el presente. Las piedras de los edificios hablan el lenguaje de los sueños, es como si la ciudad tuviera memoria (Tonkiss, 2005: 120). A partir de aquí surge la reflexión sobre el pasado en el presente para comprobar hasta qué punto las ruinas pasadas se pueden repetir en la actualidad, o si bien el ser humano ha derivado su camino hacia otros senderos. En «The Scarlet House» se muestra como el resultado que el Conde quiere lograr cuando instaure el caos (417). Al no presentarse un contacto directo con ellas, las ruinas son solo parte del recuerdo de la narradora y, a partir de ahí, un motivo de reflexión sobre el tiempo.

Otra de las imágenes que se han utilizado para explicar el fenómeno histórico es la del laberinto. Ya se comentó la alusión al mito de Ariadna y el Minotauro en «The Scarlet House». Además, hay un momento en la narración en la que la protagonista compara su mente con un laberinto (422). Luego, describe los tapices que decoran el vestíbulo del Conde de esta manera: «It's a maze of cells like the inside of a brain» (423). En ello insiste más tarde para referirse a su estado mental (424). Al final del relato, vuelve a hacer una referencia al respecto, cuando la narradora se compara con un conejo ubicado en las callejuelas de la memoria (427), con lo que vuelve al halcón cazando a su presa. El laberinto es una estructura compleja en la que hay un caos planeado: Encontrar el camino desde la entrada hasta el centro y volver desde ahí a la salida, un reto que se complica por los errores, las bifurcaciones, los giros, los caminos sin salida y en el que la labor es más compleja si, como sucede en el 
laberinto de Creta, hay un monstruo en el centro. Pero esa percepción del laberinto depende de la posición que ocupe cada sujeto (Doob, 1990: 1), algo que se refleja en este relato de Angela Carter en la manera en la que el personaje principal está experimentando su cautiverio y la forma en que lo vive el lector al llegarle la información por medio de trozos de diferentes relatos.

La Historia también se ha tratado de explicar como un proceso marcado por un destino ya establecido (Biddiss, 1997; Flórez, 1980: 84). La actividad simbólica del pensamiento mítico apuntaba a una explicación total del origen del cosmos y del destino de los seres que lo habitan (Barash, 2011: 330-331). No obstante, Platón lo veía de una manera distinta: «In the myth of Er in the Republic he shows individual souls choosing their own daimon, fate in life, before rebirth, but more usually the Greeks believed that one's fate was allotted» (Howatson, 2013: 182). Un pensamiento que difería de los mitos, ya que esta idea de Platón sobre la elección del destino implica una consciencia sobre la decisión a tomar y la relevancia posterior que va a tener para quien la toma y para los demás. Se trata de dos planteamientos que tuvieron seguimiento en los siglos posteriores, siendo Immanuel Kant (1724-1804) partidario de un destino insoslayable que el ser humano tiene que seguir, algo que apunta en Ideas para una historia universal en clave cosmopolita (1784), en concreto en el octavo principio (Kant, 1994: 17); por otro lado, Ralph Waldo Emerson (1803-1882) consideraba: «If we must accept Fate, we are not less compelled to affirm liberty» (Emerson, 2018: 251), ya que la libertad y el destino no son términos contrapuestos sino que están ligados, puesto que el ser humano posee la libertad de elegir y aceptar ese destino (Richardson, 1995: 502). En «The Scarlet House» se llega a comentar que el momento de la captura de estas mujeres que se encuentran ahora prisioneras ha marcado cuál va a ser su destino (418). La protagonista habla de su propio destino cuando desciende del carruaje e intuye lo que le puede suceder desde ese momento (421). Aunque no es una idea que aparezca siempre con nitidez, ya que en su recuerdo sobre el halcón confiesa que entonces no era consciente de cuál podía ser su destino (427). Más tarde se comprobará si la protagonista cambia su percepción sobre lo que para ella significa dicho concepto.

Otro enfoque que ha buscado explicar la Historia ha sido por medio de la experimentación de la misma de modo fenomenológico. En lo que se refiere a la materia histórica, Maurice Merleu-Ponty (1908-1961) radicalizó la filosofía fenomenológica de Edmund Husserl (1859-1938), que pretendía alcanzar el 
conocimiento por medio de las manifestaciones de la conciencia, de las estructuras de la experiencia subjetiva y, en ese sentido, se ha indicado lo siguiente: «[D]emostró que las esencias no son ahistóricas, sino el resultado de la sedimentación de intuiciones y conocimientos empíricos» (García Canclini, 1979: 11). Y si existen intuiciones y datos empíricos es porque ambos elementos forman partes constitutivas de la Historia, por lo que se justifica un acercamiento a la Historia que vaya más allá de la exégesis, el análisis y la crítica y que busque una comprensión total donde se consideren estados de ánimo, de consciencia y de aquellos aspectos que ayuden a entender la Historia como un fenómeno global, dado su carácter inabarcable. La literatura se presenta como un medio ideal para poder trasladar esta fusión de elementos donde los sentidos cobran relevancia. Por eso, cuando la protagonista logra refutar la validez de la pseudomemoria del tren y el carruaje lo hace en base a que el material que la compone tiene cierto sabor literario, de ahí que llegue a la conclusión de que tiene olor a pseudomemoria. El mismo sentido está presente cuando recuerda la fragancia de las flores de su casa paterna (421). Es tan consciente de la validez de esta forma de experimentar su propia historia que cuando trata de recordar al halcón se dice a sí misma que se debe concentrar en experiencias físicas (427).

Considerando la relación entre la Historia y la ficción dentro de la postmodernidad resulta casi inevitable mencionar Metahistory (1973) de Hayden White (1928-2018). Este historiador propone un acercamiento a la Historia en base a tropos, ya que en el origen del discurso histórico se encuentra la memoria, que no puede recordarlo todo. Ante la imposibilidad de acceder al pasado histórico y que la historiografía expone los sucesos de forma lineal, como las propias narraciones mitológicas y folklóricas, se acepta que un mismo relato pueda tener distintas lecturas desde diferentes enfoques, por lo que las interpretaciones pueden ser infinitas (Jenkins, 1991: 11). Ante esta situación, los discursos histórico y literario se equiparan en su validez, puesto que se muestran ligados desde sus orígenes y solo quedaría una aproximación literaria a la Historia.

En la resolución de «The Scarlet House» la protagonista vence cuando acepta que el caos está en el origen de la memoria, como lo está en el origen del universo, y admite que en la refutación de la Historia está su liberación cuando es consciente de que no va a salir de la mazmorra, o laberinto, en el que se encuentra, que su visión no es completa ni lo va a ser pero, al mismo 
tiempo, necesita tener presente todo esto por medio de su recuerdo mnemotécnico. Tanto el cochero de la segunda memoria como los motoristas no tienen boca para poder expresarse porque ya están atrapados en el mundo del Conde y la protagonista quiere evitar ser una nueva presa, de ahí que afirme al final del relato: «When I perceived I'd organised these disparate elements into a grid, or system of connections, I felt for the first time I entered the obscure portals of the Scarlet House, a flood of joy» (428). Ella se describía al principio de la narración contemplando el paisaje como una naturalista (417), y es que su capacidad de observación histórica ha hecho que sistematice elementos inconexos entre sí y por eso ahora percibe la casa de una nueva forma, puesto que ha entendido que es el lugar en el que va a estar siempre, por eso escribe al final desde la perspectiva metahistórica que ha alcanzado. Aunque existan rasgos que permitan descartar la verosimilitud de ciertas partes de las pseudomemorias, la protagonista acepta la utilidad de aquellos elementos (residuos) que le ofrecen mayor credibilidad para darle a todas las memorias la misma validez. Es la forma que tiene para controlar ahora el juego. Este hallazgo metahistórico se podría comparar con el descubrimiento de algún mensaje cifrado que permanece ignoto para los no iniciados en un campo, como sucede con los adornos («patterns») cabalísticos en las chaquetas de los motoristas.

Esta liberación que ha obtenido la protagonista no es únicamente individual. En el relato, la narradora muestra su solidaridad con las otras prisioneras. Aquí emerge de nuevo la analogía con la caverna de Platón, donde una de sus posibles interpretaciones es en clave política, con el prisionero liberando y dirigiendo a sus compañeros hacia la luz. Así, la protagonista de «The Scarlet House» comparte con los lectores la clave metahistórica que ha alcanzado al final de su narración para desencadenarlos y, al mismo tiempo, estaría arrojando luz sobre la situación en la que estos se encuentran, que no parece ser muy diferente de la del resto de las prisioneras del relato.

\section{CONCLUSIÓN}

En la obra de Angela Carter se pueden encontrar rasgos postmodernos como son la hipertextualidad y la reescritura de textos. En cuanto a la temática, el presente estudio quiere llamar la atención sobre la presencia que tiene 
la Historia en la producción de la citada autora. En este sentido, se han destacado la defensa de una historia individual que incluya a todos los miembros de la comunidad como partícipes de la Historia, las conexiones entre la Historia y la ficción, el palimpsesto como imagen de las posibles interpretaciones que puede recibir un texto y, por último, la importancia de la memoria en el discurso histórico. Teniendo en cuenta todo ello, se propone un punto de vista alternativo de su relato «The Scarlet House» desde la filosofía de la Historia.

El estado cognitivo en el que se encuentra la narradora del relato y sus deseos por abandonar la casa hacen que busque orientación en distintos campos de conocimientos. La imagen del halcón es un recurso mnemotécnico que remite a la memoria, mientras que las ruinas y el laberinto apuntan a la posición que se puede ocupar ante la Historia. La intención de buscar ayuda en la experimentación fenomenológica de la Historia sigue la misma línea. En cuanto al destino, con la decisión final la protagonista cambia su idea primigenia y, tomando el control, logra un grado de libertad de elección que, al mismo tiempo, conlleva el compromiso por liberar a las otras mujeres.

Por este motivo es interesante la analogía que existe en este punto con la alegoría de la caverna de Platón, donde el prisionero entra de nuevo en la caverna para liberar a los que todavía se encuentran encadenados, estos se burlarían de él y pensarían que sus ojos han quedado cegados por la luz solar. En el caso de la protagonista de «The Scarlet House», las incongruencias que muestra desde un primer momento y la mezcla de fragmentos no ordenados de tres pseudomemorias pueden hacer pensar al lector que está desorientada, que no es una narradora fiable. Al principio, el lector puede que no sea consciente de su propia posición en la Historia, o puede no considerar esta intención en el relato, pero el giro final lo sitúa dentro del laberinto de la Historia, en un lugar similar al de las prisioneras. En este punto, la experiencia de la narradora, que ya la ha transformado, surge para ofrecer una revelación en clave metahistórica. Por todo ello, habría que considerar a la filosofía de la Historia como otro posible campo de conocimiento dentro del complejo entramado de modelos presentado y, en consecuencia, la pertinencia de interpretar «The Scarlet House» desde esta óptica que, con la ayuda de la alegoría de la caverna, invitaría a alcanzar un nuevo grado epistemológico a todo aquel que se acerque a la lectura de esta narración. 


\section{BIBLIOGRAFÍA CITADA}

AlbaigÉs, J.M. (2014): El numeronomicón. Diccionario de números, sus propiedades matemáticas, tradición histórica y simbolismo. Madrid, Tébar Flores.

BACCHILEGA, C. (2015): «Fairy-tale Adaptations and Economies of Desire». En Tatar, M. (ed.): The Cambridge Companion to Fairy Tales. Cambridge, CUP, págs. 7996.

BARASH, J.A. (2011): «Myth in History, Philosophy of History as Myth: On the Ambivalence of Hans Blumenberg's Interpretation of Ernst Cassirer's Theory of Myth». History and Theory, 50, págs. 328-340.

BARTHES, R. (1984): «El efecto de realidad». En Barthes, R.: El susurro del lenguaje. Trad. C. Fernández Medrano. Barcelona, Paidós, págs. 179-188.

Beneduce, R. (2017): «History as Palimpsest. Notes on Subalternity, Alienation, and Domination in Gramsci, De Martino and Fanon». International Gramsci Journal, 2.3, págs. 134-173.

BIDDISS, M. (1997): «History as Destiny: Gobineau, H.S. Chamberlain and Spengler». Transactions of the Royal Historical Society, 7, págs. 73-100.

Berni, C. (1997): «Taking an Axe to History: The Historical Lizzie Borden and the Postmodern Historiography of Angela Carter». Clio, 27.1, págs. 29-55.

Botelho, I. (2016): «Destroying and Creating Identity: Vampires, Chaos and Society in Angela Carter's 'The Scarlet House'». En Ermida, I. (ed.): Dracula and the Gothic in Literature, Pop Culture and the Arts. Leiden, Brill Rodopi, págs. 293308.

Calvo López, C. (2012): «Shakespeare, Austen y Angela Carter: Padres e hijas en Wise Children». En De la Concha, M.A. (ed.): Shakespeare en la imaginación contemporánea. Revisiones y reescrituras de su obra. Madrid, UNED, págs. 143-170.

CARTER, A. (1985): «The Company of Angela Carter: An Interview». Marxism Today, págs. 20-22.

- (2001): The Sadeian Woman. London, Penguin.

— (ed.) (2005): Angela Carter's Book of Fairy Tales. London, Virago.

- (2006): Burning Your Boats: Collected Short Stories. London, Vintage.

- (2013): «Notes from the Front Line». En Carter, A.: Shaking a Leg: Collected Journalism and Writings. London, Vintage, págs. 45-53.

Chevalier, J., y Gheerbrant, A. (2007): Diccionario de los símbolos. Trad. M. Silvar y A. Rodríguez. Barcelona, Herder.

Crunelle-VAnrigh, A. (2001): «The Logic of the Same and Difference: The Courtship of Mr. Lyon». En Roemer, D.M. y Bacchilega, C. (eds.): Angela Carter and the Fairy Tale. Detroit, Wayne State University Press, págs. 128-144. 
Donnelly, M. y Norton, C. (2011): Doing History. London Routledge.

Doob, P.R. (1990): The Idea of the Labyrinth from Classical Antiquity Through the Middle Ages. Ithaca, Cornell University Press.

DutheIL de la Rochère, M.H. (2013): Reading, Translating, Rewriting: Angela Carter's Translation Poetics. Detroit, Wayne State University Press.

EMErson, R.W. (2018): «Fate». En Habish, R.D. (ed.): Selected Writings of Ralph Waldo Emerson. Peterborough, Broadview Press, págs. 250-277.

Filimon, E.C. (2014): Heterotopia in Angela Carter's Fiction: World in Collision. Hamburg, Anchor Academic Publishing.

Flórez Miguel, C. (1980): La filosofía contemporánea. Salamanca, Universidad de Salamanca.

GARCÍA BARRERA, I. (1999): «Caos y (seudo-)memoria(-s) en 'The Scarlet House' de Angela Carter». Philologia Hispalensis, 13.2, págs. 139-145.

García CANCLINI, N. (1979): Epistemología e historia. La dialéctica entre sujeto y estructura en Merleau-Ponty. México, UNAM.

Gómez-Lobo, A. (1995): «Las intenciones de Herodoto». Estudios Públicos, 59, págs. 1-16.

Heródoto (1994): Historias. Libros V-IX. Trad. A. González Caballo. Madrid, Akal.

Howatson, M.C. (ed.) (2013): Oxford Companion to Classical Literature. Oxford, OUP.

Hutcheon, L. (2004): A Poetics of Postmodernism: History, Theory, Fiction. New York, Routledge.

JAmeson, F. (2002): The Political Unconscious: Narrative as a Socially Symbolic Act. London, Routledge Classics.

JEnkins, K. (1991): Rethinking History. London-New York, Routledge.

KANT, I. (1994): Ideas para una historia universal en clave cosmopolita y otros escritos sobre filosofía de la historia. Trad. C. Roldán y R. Rodríguez. Madrid, Tecnos.

KéRCHY, A. (2019): «Psychogeography in the Curiosity Cabinet: Angela Carter's Poetics of Space». En Mulvey-Roberts, M. (ed.): The Arts of Angela Carter: A Cabinet of Curiosities. Manchester, MUP, págs. 39-57.

Lowenthal, D. (1998): El pasado es un país extraño. Trad. P.A. Piedras Monroy. Madrid, Akal.

MCCAw, N. (2000): George Eliot and Victorian Historiography: Imagining the National Past. Basingstoke, Palgrave MacMillan.

MARIÑO FERRO, J.R. (1996): El simbolismo animal: creencias y significados en la cultura occidental. Madrid: Encuentro. 
MĂTEL-BoAtcĂ, M. (2011): «Intertextuality in Angela Carter's Short Stories». Studia Ubb Philologia, LVI.4, págs. 57-72.

Okuhata, Y. (2019): Angela Carter's Critique of Her Contemporary World: Politics, History, and Mortality. London, Birkbeck University of London (en línea: <http://bbktheses.da.ulcc.ac.uk/442/1/cp_PhD_Thesis.pdf>, consulta: 4 diciembre 2019).

PÉRez Gil, M.M. (1996): La subversión del poder en Angela Carter. Las Palmas de Gran Canaria, Universidad de Las Palmas de Gran Canaria.

- (2016): "A Vampire in Plato's Cave: Mimesis, Anamorphosis, and Simulacra in Angela Carter's 'The Lady of the House of Love'». Critique: Studies in Contemporary Fiction, 57.5, págs. 512-520.

Platón. (2004): La República. Santa Fe, El Cid Editor.

RichaRdSON, R.D. (1995): Emerson: The Mind on Fire. Berkeley, University of California Press.

Ricoeur, P. (1988): Time and Narrative, vol. I. Trad. K. Blamey y D. Pellauer. Chicago, University of Chicago Press.

Roemer, D.M. (1998): «The Contextualization of the Marquis in Angela Carter's 'The Bloody Chamber'». Marvels \& Tales, 12.1, págs. 95-115.

SEMPRUCH, J. (2008): Fantasies of Gender and the Witch in Feminist Theory and Literature. West Lafayette, Purdue University Press.

Sturken, M. (1997): «Reenactment, Fantasy, and the Paranoia of History: Oliver Stone's Docudramas». History and Theory, 36.4, págs. 64-79.

TONkISS, F. (2005): Space, the City and Social Theory: Social Relations and Urban Forms. Cambridge, Polity Press.

Vlitos, P. (2017): “'See! The Angel of Death!’: Lizzie Borden, Angela Carter and l'effet de reel». Textual Practice, 31.7, págs. 1399-1416.

Emilio José Álvarez CASTAÑo Zhejiang Yuexiu University of Foreign Languages telemilio@yahoo.es 0000-0001-7020-9676 
